\title{
CATALASE ACTIVITY AND ISONIAZID SENSITIVITY OF TUBERCLE BACILLI
}

\author{
BY \\ A. BECK \\ From the Pathology Department, Paddington General Hospital, London
}

(RECEIVED FOR PUBLICATION JANUARY 25, 1957)

In 1954 Middlebrook reported the loss of catalase activity in tubercle bacilli which had become resistant to isoniazid. This observation was broadly confirmed by Nassau and Hamilton (1955), Neumayr, Morse, and Morse (1955), Marseille (1955), and Knox, Meadow, and Worssam (1956). Peizer and Widelock (1955), however, failed to find a consistent relationship between isoniazid sensitivity and catalase activity.

Since the catalase test is easily performed and gives an immediate result, it would obviously be of value as a presumptive indicator of isoniazid resistance if it were proved to be consistently negative in isoniazid-resistant cultures. In order to obtain information on this point 116 cultures of tubercle bacilli examined in this laboratory during the last nine months for their sensitivity to anti-tuberculosis drugs were also tested for their catalase activity.

\section{Experimental}

With a few exceptions, cultures were tested for their sensitivity to three drugs, i.e., isoniazid, streptomycin, and P.A.S. The tests were carried out on Löwenstein media to which these drugs were added before inspissation. The final drug concentrations in $1 \mathrm{ml}$. of media were : I.N.H., $0.2,1,5,10$, and $50 \mu \mathrm{g}$., and P.A.S., 14, 16, and $64 \mu \mathrm{g}$.; streptomycin was added to the medium to give initial concentrations of 10 and $100 \mu \mathrm{g} . / \mathrm{ml}$. and expected final concentrations of about 3 and $30 \mu \mathrm{g} . / \mathrm{ml}$., when allowance is made for loss of about two-thirds of this drug by heating and binding to the medium. The tests were read after four weeks' incubation when the control cultures grown on medium without drugs were examined for the presence of catalase.

The catalase test was carried out by Middlebrook's method (Middlebrook, 1954). Equal quantities (3.5 $\mathrm{ml}$.) of a $10 \%$ aqueous solution of Tween 80 and of a 100-volume solution of hydrogen peroxide were added to a Löwenstein culture in a $\frac{1}{2}$-oz. screwcapped bottle so that the entire growth was submerged. A positive reaction manifested itself in the rapid liberation of bubbles of oxygen in the vicinity of the growth which on rising collected as a foam on top of the fluid. The intensity of the reaction varied between the formation of a big head of foam within 30 seconds $(+++$ reaction) and the collection of a few gas bubbles over a period of three minutes ( \pm reaction).

\section{Results}

The results of these tests are summarized in Table I. It will be seen from this table that all

TABLE I

CATALASE PRODUCTION AND RESISTANCE TO ISONIAZID OF 116 CULTURES

\begin{tabular}{|c|c|c|c|}
\hline \multirow{2}{*}{\multicolumn{2}{|c|}{ Isoniazid Concentration }} & \multicolumn{2}{|c|}{ No. of Cases } \\
\hline & & Catalase-positive & Catalase-negative \\
\hline \multirow[t]{2}{*}{ 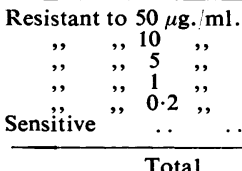 } & $\begin{array}{l}. \\
. \\
\ldots \\
.\end{array}$ & $\begin{array}{l}8(7)^{*} \\
1(1) \\
3(3) \\
5(5) \\
6(6) \\
69(8)\end{array}$ & $\begin{aligned} & 15(9) \\
& 3(2) \\
& 1(1) \\
& 4(3) \\
& 1(-) \\
& 0\end{aligned}$ \\
\hline & & 92 & 24 \\
\hline
\end{tabular}

* The figures in brackets indicate the number of cultures which, in addition to being resistant to isoniazid, were also resistant to streptomycin and /or P.A.S.

24 catalase-negative cultures were resistant to isoniazid. Although the majority (18) of these were highly resistant to this drug $(10 \mu \mathrm{g} . / \mathrm{ml}$. or more) there were five cultures with a resistance to only $1 \mu \mathrm{g}$. or less. On the other hand, all 69 isoniazid-sensitive cultures gave a positive catalase reaction. This varied in intensity from + to +++ , only four cultures giving a very weak $( \pm)$ reaction. There were, however, 23 cultures which were isoniazid resistant and catalase positive. Nine of these were of high $(10 \mu \mathrm{g} . / \mathrm{ml}$. or more) and 14 of intermediate or weak resistance $(0.2-5 \mu \mathrm{g} . / \mathrm{ml}$.). Two were atypical chromogenic acid-fast bacilli whose resistance to isoniazid and strongly positive catalase reaction constitute almost diagnostic features.

There was a slight difference in the incidence of multiple drug resistance in the catalase-positive and -negative groups. Twenty-two of the 23 isoniazid-resistant, catalase-positive cultures were also resistant to streptomycin or P.A.S. or both, 
whereas only 15 of the 24 catalase-negative cultures showed multiple drug resistance. In agreement with previous observers, no loss of catalase activity was seen in cultures which were resistant only to streptomycin or P.A.S. or to the combination of the two.

\section{Discussion}

From these observations it can be concluded that tubercle bacilli which fail to produce catalase are usually resistant to isoniazid. There appears to be no critical drug concentration at which loss of catalase production can be expected. Although it is, on the whole, associated more frequently with highly resistant cultures it can be found in cultures with low degrees of resistance.

The finding of a number of isoniazid-resistant cultures which produced catalase shows that a positive catalase test cannot be taken to indicate sensitivity to isoniazid. Similar observations were made by Cohn, Kovitz, Oda, and Middlebrook (1954), Nassau and Hamilton (1955), and Wolinsky, Smith, and Steenken (1956), who also demonstrated that these cultures retain their virulence in contrast with catalase-negative, isoniazid-resistant strains which are usually avirulent. It is possible that they owe the persistence of their virulence and power to produce catalase to the presence of a few isoniazid-sensitive bacilli which are masked by the bulk of isoniazid-resistant growth. Although some difference was found in the incidence of multiple drug sensitivity in this group and the group of catalase-negative, isoniazid-resistant cultures it is not large enough to allow of any conclusion.

\section{Summary}

One hundred and sixteen cultures of tubercle $\stackrel{\vec{S}}{\stackrel{F}{9}}$ bacilli were tested for catalase production ando sensitivity to isoniazid, streptomycin, and P.A.S. 흘 A negative catalase test was always associated $\frac{\bar{\rho}}{\frac{\sigma}{\sigma}}$ with some degree of resistance to isoniazid. $A \stackrel{\mathbb{\Omega}}{\Omega}$ positive catalase test, however, did not exclude resistance to this drug, since 23 out of 92 catalasepositive cultures were isoniazid resistant. All. isoniazid-sensitive cultures produced catalase.

\section{Addendum}

Since the completion of this paper a further $117 \vec{\circ}$ cultures of tubercle bacilli have been tested for: catalase production with results confirming the above conclusions. Nine of these were catalase $\overrightarrow{ }$ positive and resistant to at least $5 \mu \mathrm{g} . / \mathrm{ml}$. of $\frac{\text { 을 }}{2}$ isoniazid; when tested on a medium containing the highest concentration of isoniazid compatibleo with their growth they all failed to produce cata-市 lase. The results with this modified technique 3 confirm the assumption that such cultures consist黑 of a mixed population of isoniazid-sensitive, cata- $\overrightarrow{0}$ lase-positive and isoniazid-resistant, catala\&-c negative bacilli.

\section{REFERENCES}

Cohn, M. L., Kovitz, C., Oda, V., and Middlebrook, G. (19 $\left.\frac{54}{4}\right)$ Amer. Rev. Tuberc., 70, 641 .

Knox, R., Meadow, P. M., and Worssam, A. R. H. (1956). Ibid. 73, 726.

Marseille, A. (1955). Ned. T. Geneesk., 99, 619.

Middlebrook, G. (1954). Amer. Rev. Tuberc., 69, 471.

Nassau, E., and Hamilton, G. M. (1955). Tubercle (Lond.), 36. 281

Neumayr, R. B., Morse, B. Z., and Morse, W. C. (1955). Proc. Soc 3 exp. Biol. (N.Y.), 89, 468 .

Peizer, L. R., and Widelock, D. (1955). Amer. Rev. Tuherc., 72, 246

Wolinsky, E., Smith, M. M.. and Steenken, W., Jr. (1956). Ibid.O 73, 768 . 